\title{
Latitudinal Change of Tropical Cyclone Maximum Intensity in the Western North Pacific
}

\author{
Jae-Won Choi, ${ }^{1}$ Yumi Cha, ${ }^{2}$ Hae-Dong Kim, ${ }^{3}$ and Sung-Dae Kang ${ }^{4}$ \\ ${ }^{1}$ National Institute of Meteorological Research, Jeju, Republic of Korea \\ ${ }^{2}$ National Typhoon Center, Korea Meteorological Administration, Jeju, Republic of Korea \\ ${ }^{3}$ Department of Global Environment, Keimyung University, Daegu, Republic of Korea \\ ${ }^{4}$ Green Simulation, Co., Ltd., SK HUB-SKY, 1523 Jungangdae-ro, Dongrae-gu, 102-3004 Busan, Republic of Korea
}

Correspondence should be addressed to Hae-Dong Kim; khd@kmu.ac.kr

Received 6 July 2015; Revised 23 July 2015; Accepted 29 July 2015

Academic Editor: Xiaofeng Li

Copyright (c) 2016 Jae-Won Choi et al. This is an open access article distributed under the Creative Commons Attribution License, which permits unrestricted use, distribution, and reproduction in any medium, provided the original work is properly cited.

\begin{abstract}
This study obtained the latitude where tropical cyclones (TCs) show maximum intensity and applied statistical change-point analysis on the time series data of the average annual values. The analysis results found that the latitude of the TC maximum intensity increased from 1999. To investigate the reason behind this phenomenon, the difference of the average latitude between 1999 and 2013 and the average between 1977 and 1998 was analyzed. In a difference of $500 \mathrm{hPa}$ streamline between the two periods, anomalous anticyclonic circulations were strong in $30^{\circ}-50^{\circ} \mathrm{N}$, while anomalous monsoon trough was located in the north of South China Sea. This anomalous monsoon trough was extended eastward to $145^{\circ}$ E. Middle-latitude region in East Asia is affected by the anomalous southeasterlies due to these anomalous anticyclonic circulations and anomalous monsoon trough. These anomalous southeasterlies play a role of anomalous steering flows that make the TCs heading toward region in East Asia middle latitude. As a result, TCs during 1999-2013 had higher latitude of the maximum intensity compared to the TCs during 1977-1998.
\end{abstract}

\section{Introduction}

The number of tropical cyclones generated in the western North Pacific is about 30 cyclones every year, which is relatively more than TCs generated in other oceans (Indian Ocean, Eastern Pacific, and western North Pacific). Most of them are landed on a number of East Asia nations including Korea that are adjacent to the western North Pacific, thereby resulting in economic damage and casualties enormously. In particular, TC intensity has a positive correlation with damages it causes so that a large number of studies have been conducted on the variation of the western North Pacific TC intensity over the past few years. Some studies including Emanuel [1] showed that as the sea surface temperature in the western North Pacific increased in recent years TC intensity has also been strengthened.

In the Western Pacific region, a large amount of property damages and casualties has occurred every year due to tropical cyclones (TCs) generated in the tropical and subtropical western North Pacific. In Japan, 10 TCs were landed in 2004, which was still recorded the highest year that is not broken [2]. In Korea, Typhoon Rusa was landed in 2002, pouring the maximum accumulated rainfall of $870.5 \mathrm{~mm}$ in Gangneung, which was the all-time record high up until now in Korea [3]. In Taiwan, Typhoon Morakot was landed in 2009 , pouring rainfall in one day that was equivalent to an annual amount of accumulated rainfall [4]. In the Philippines, about 10 TCs were landed every year, which revealed the highest TC frequency in East Asia [5]. In particular, super Typhoon "Haiyen" struck the Leyte province located in the middle of the Philippines in November 8, 2013, which was the largest TC ever recorded in the Philippines. The maximum sustained wind speed of the TC was recorded as $379 \mathrm{~km}$ per hour, which was 1.5 times stronger than "Maemi" the worst TC ever recorded in Korea and even worse than "Katrina" in the USA. "Haiyen" caused a large number of casualties as well as property damage as $6 \mathrm{~m}$ high tidal waves with storing wind swept over the middle of the Philippines. Although it is not 
confirmed yet, the number of deaths and missing caused by the TC was over 5,000 and victims over 4 million suffered from interruption of electricity and water supply as well as food shortage. In particular, about $95 \%$ of Tacloban city was completely destroyed and changed into a huge landfill $[6,7]$.

However, it is difficult to make a conclusion definitely regarding the increase of TC intensity due to the lack of reliable long-term observation data with respect to the variation of TC intensity [8]. This is because TCs are affected by various factors other than sea surface temperature such as vertical wind shear and lower-level relative vorticity in addition to inaccuracies of the TC observation data [9]. Nonetheless, recently published studies reported that frequency of strong TCs that had more than category 4 , their duration, and their intensity have increased since 2000s and many researchers view that this phenomenon is due to the effect of global warming caused by fossil fuel emission [10]. Chu and Clark [11] also proved that the recent increase of influence by TCs with strong intensity was also found in the central Pacific noticeably. In general, global warming due to the greenhouse effect has been accepted as the reason for such increase of TC frequency and intensity in recent years.

Recently, Kamahori et al. [12] emphasized that it was necessary to be prepared for TCs with strong intensity since intense TC days have increased steadily for the recent 30 years. Similar to the above study result, Elsner et al. [13] also reported that all TC basins except for South Pacific Ocean basin experienced increased intensity of strong TCs. In particular, they proved that such increase was more evident in North Atlantic and North Indian Ocean basins.

In contrast with the above results, there are other studies that claim that TC intensity has become weakened. Landsea et al. [14] emphasized that intense hurricane frequency has decreased in the Atlantic Ocean over the last 50 years. Ho et al. [15] also proved through statistical change-point analysis that TC annual frequency and TC intensity have decreased in the East China Sea since the mid-1970s while the declining trend was more evident near the Philippines. As an extension of a study by Chan and Shi [16], Chan [17] fitted TC intensity data in Northwest Pacific, which was updated up to the early 2000 s, with a second-order polynomial equation and proved that there has rather been decreased trend TC intensity since the mid-1990s. Such decreasing trend in TC intensity has also been observed in the South China Sea for the past 40 years [18].

It is also found that there are studies claiming that there has been no trend change in TC intensity. Lighthill [19] showed that there has been no significant change in TC intensity in North Atlantic, Northeast, and Northwest Pacific basins. Klotzbach [20] also mentioned that there has been no increasing trend in accumulated cyclone energy (ACE) in each TC basin over the last 20 years (1990-2006) except for minor increase of ACE in categories 4-5 hurricanes. Bove et al. [21] also discovered that there was no increasing trend in hurricane intensity landed on the Gulf of Mexico over the past century.

Recent study result also showed that latitudes that showed TC maximum intensity have been globally moved northerly $[22,23]$. They pointed out that the reason for the northerly shift was related to northerly shift of tropic regions due to global warming. However, their study also did not provide large-scale environments for the clear reason for the recent northerly latitude shift of TC maximum intensity. Thus, the present study aims to determine whether recent northerly latitude shift of TC maximum intensity is found and to analyze large-scale environments for this shift.

Section 2 in the present study introduces data and analysis method, while Section 3 presents statistical change-point analysis with respect to the latitude change of TC maximum intensity. Section 4 analyzes large-scale environments for the latitude change of TC maximum intensity between the periods before and after 1999. Section 5 concludes this study.

\section{Data and Methodology}

2.1. Data. The TC data in this study was obtained from the best-track of TC provided by Regional Specialized Meteorological Center- (RSMC-) Tokyo Typhoon Center. This data consists of TC name, latitude and longitude location of TC, TC central pressure, and TC maximum sustained wind speed (MSWS), which were observed in every 6 hours for 35 years from 1977 to 2013. TC is generally classified into four classes by the criteria of MSWS as follows: Tropical Depression (TD, MSWS $<17 \mathrm{~ms}^{-1}$ ), Tropical Storm (TS, $17 \mathrm{~m} \mathrm{~s}^{-1} \leq$ MSWS $\leq$ $24 \mathrm{~m} \mathrm{~s}^{-1}$ ), Severe Tropical Storm (STS, $25 \mathrm{~m} \mathrm{~s}^{-1} \leq$ MSWS $\leq$ $32 \mathrm{~m} \mathrm{~s}^{-1}$ ), and Typhoon (TY, MSWS $\geq 33 \mathrm{~m} \mathrm{~s}^{-1}$ ). Along with the four classes of TC above, this study included extratropical cyclone, which was transformed from TC for analysis. This was because such extratropical cyclone also incurred great damage on property and human in the mid-latitude regions in East Asia.

Moreover, this study also used the variables of geopotential height (gpm), zonal and meridional winds $\left(\mathrm{ms}^{-1}\right)$, relative humidity $(\%)$, and air temperature $\left({ }^{\circ} \mathrm{C}\right)$ data from National Centers for Environmental Prediction-National Center for Atmospheric Research (NCEP-NCAR) reanalysis in 1977 to $2013[24,25]$. This NCEP-NCAR reanalysis data consisted of spatial resolution such as latitude and longitude $2.5^{\circ} \times 2.5^{\circ}$ and 17 vertical levels (relative humidity is 16 vertical levels).

Also, the National Oceanic and Atmospheric Administration (NOAA) interpolated outgoing longwave radiation (OLR) data retrieved from the NOAA satellite series are available starting from June 1974 from NOAA's Climate Diagnosis Center (CDC). However, the data are incomplete, with a missing period from March to December of 1978. Detailed information about this OLR data can be found on the CDC website (http://www.cdc.noaa.gov/) and in the study by Liebmann and Smith [26].

The NOAA extended reconstructed monthly sea surface temperature (SST) [27], available from the same organization, was also used. The data have a horizontal resolution of $2.0^{\circ} \times 2.0^{\circ}$ latitude-longitude and are available for the period of 1854 to the present day.

2.2. Methodology. To calculate the TC passage frequency, each position of a TC is binned into a $5^{\circ} \times 5^{\circ}$ grid box, and a TC is only counted once, although it may enter the same grid 
box several times [28]. The TC genesis frequency is calculated by the same method as for the TC passage frequency. The range of the latitudes/longitudes where the TCs are analyzed is $0-70^{\circ} \mathrm{N}$ and $95^{\circ}-185^{\circ} \mathrm{E}$.

This study used Student's $t$-test to determine significance [29]. In case that two independent time series follow $t$ distribution and their time averages are denoted as $\overline{x_{1}}$ and $\overline{x_{2}}$, respectively, the test statistic is given by

$$
t=\frac{\overline{x_{1}}-\overline{x_{2}}}{\left(s_{1}^{2} / n_{1}+s_{2}^{2} / n_{2}\right)^{1 / 2}}
$$

where $s_{1}$ and $s_{2}$ are standard deviations and $n_{1}$ and $n_{2}$ are numbers of the two time series, respectively. From the above formula, if the absolute value of $t$ is greater than threshold values with a level of significance, the null hypothesis would be rejected at the $\alpha(\times 100) \%$ significance level.

With a trend change, statistical change-point analysis was conducted to determine whether climate regime shift existed in the time series of 35 years. Because this variable does not follow Poisson distribution, we use a different method to detect climate regime shifts in the temperature or TC frequency series: using a log-linear regression model in which a step function is expressed as an independent variable. If the estimated slope is at least twice as large as its standard error, one may reject the null hypothesis (i.e., the slope being zero) at the $5 \%$ significance level. The details of this method are well described in studies of Elsner et al. [30], Chu [31], and Ho et al. [15]. Once statistical change-point analysis is conducted, $t$ value is produced for every year. If absolute value of $t$ value is the largest, it means that the corresponding year had a climate regime shift.

The vertical wind shear (VWS) to diagnose the large-scale condition is calculated as follows:

$$
\text { VWS }=\sqrt{\left(u_{200-850}\right)^{2}+\left(v_{200-850}\right)^{2}} .
$$

Here, $u$ and $v$ indicate the zonal and meridional flows, respectively, and 200 and 850 represent $200 \mathrm{hPa}$ and $850 \mathrm{hPa}$ levels, respectively [32].

This study analyzes TCs in summer season which is defined as July-September. This is because two-thirds of TCs generated over the year are concentrated in these three months.

\section{Analysis of Climate Regime Shift on Latitude Change of TC Maximum Intensity}

Figure 1 shows a time series of annually averaged latitude of TC maximum intensity after finding all latitudes of TC maximum intensity using the maximum sustained wind speed in the RSMC best track at the interval of six hours. Overall, latitudes of TC maximum intensity shifted northerly (light face dashed line) showing clear interannual and interdecadal variations. Therefore, statistical change-point analysis was conducted with regard to this time series to determine whether climate regime shift existed. The result showed that $t$ value maintained a certain trend until 1999, followed by showing an increasing trend (dotted line). Therefore,

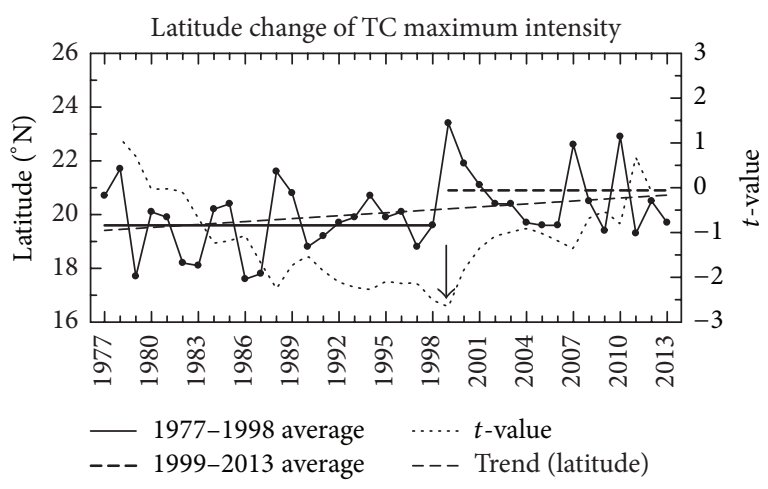

FIGURE 1: Time series of latitude of tropical cyclone (TC) maximum intensity averaged for all TCs in each year (solid line with dot) and its trend (light face dashed line). Thick solid and bold dashed lines denote averages for 1977-1998 and for 1999-2013, respectively. Arrow denotes change-point year in time series of latitude of tropical cyclone (TC) maximum intensity.

a climate regime shift year was set to 1999 in terms of latitude change of TC maximum intensity for the recent 37 years (arrow mark). The average latitude of TC maximum intensity over the years of $1977-1998$ was $19.6^{\circ} \mathrm{N}$ (thick solid line), while that of 1999-2013 was $21.2 \mathrm{~N}$ (bold dashed line), indicating a about $1.6 \mathrm{~N}$ latitude difference between two periods. Assuming that $1^{\circ}$ is equivalent to $100 \mathrm{~km}$, a latitude shift of TC maximum intensity for the recent 37 years means $160 \mathrm{~km}$ northerly shift. Here, a latitude difference between two periods is statistically significant with $95 \%$ confidence level. To determine the reason for the recent latitude shift of TC maximum intensity, a difference of means between 19992013 and 1977-1998 was analyzed.

\section{Differences between 1999-2013 and 1977-1998}

4.1. TC Activity. The present study investigated differences of TC activity between two periods (see Figure 2). The TC activity in this study refers to TC genesis frequency and TC passage frequency. With respect to the TC genesis frequency, TCs in 1999-2013 were generated more in a northwest region of the tropical and subtropical western North Pacific than TCs in 1977-1998 (see Figure 2(a)). The data of TC average genesis locations during the two periods showed that 1999-2013 was $16.8 \mathrm{~N}, 135.1 \mathrm{E}$ while $1977-1998$ was $14.9 \mathrm{~N}, 144.5 \mathrm{E}$, confirming that recent TCs were generated further in a northwest region of the tropical and subtropical western North Pacific than previous TCs. Here, differences of both TC average genesis latitude and TC average genesis longitude between the two periods were statistically significant with $95 \%$ confidence level. Accordingly, northerly latitude shift of not only TC maximum intensity but also TC genesis location was found in recent TCs through the data.

There was a clear difference of TC track pattern between two periods with respect to TC passage frequency (see Figure 2(b)). The TC track over the years of 1977-1998 showed two patterns. A first pattern is a TC track that was generated 


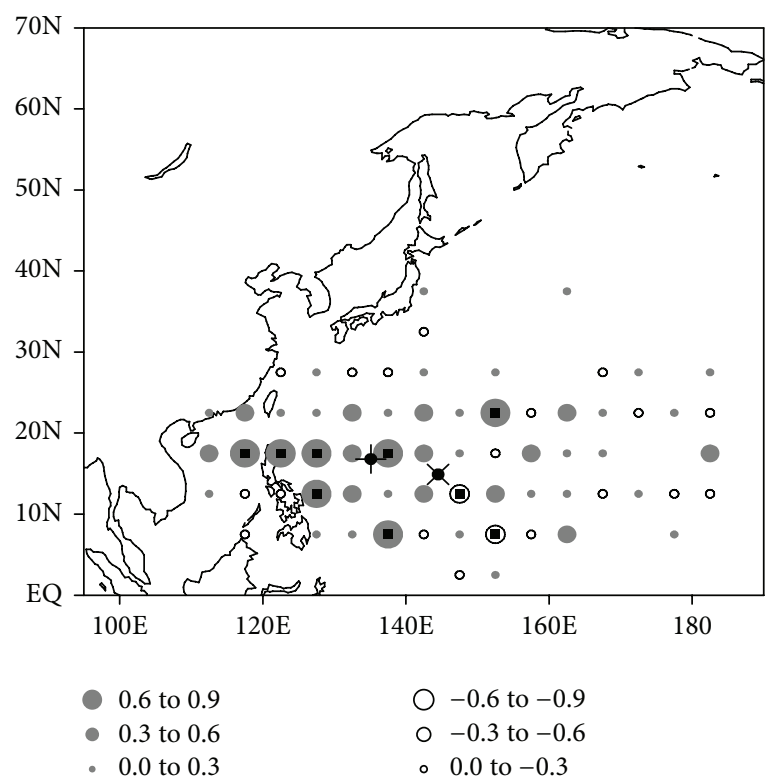

(a) TC genesis frequency

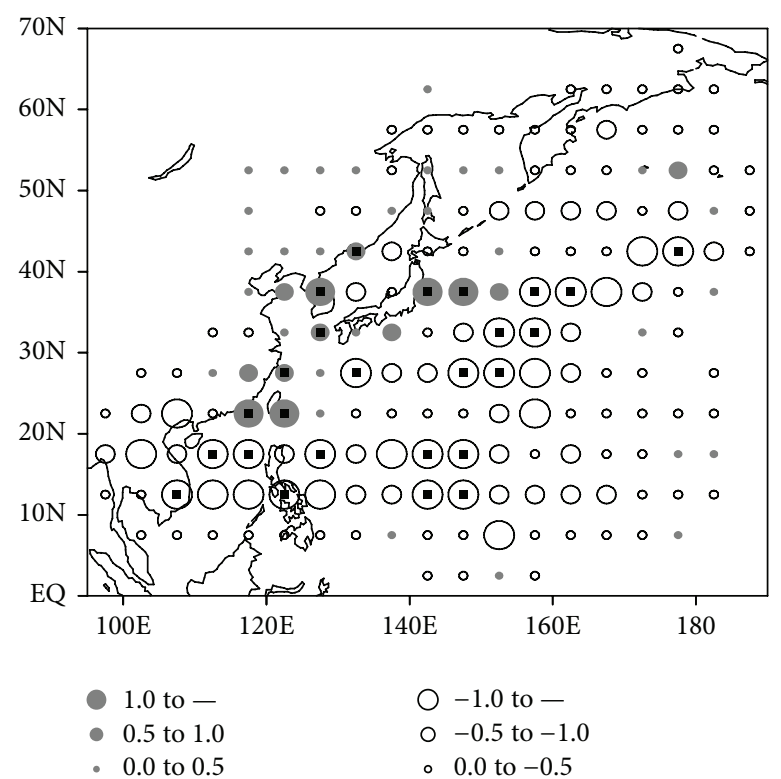

(b) TC passage frequency

FIGURE 2: Geographical distributions of difference in (a) TC genesis frequency and (b) TC passage frequency between the periods of 19992013 and 1977-1998 in each $5^{\circ} \times 5^{\circ}$ grid area. Small box inside circles indicate that differences are significant at the $95 \%$ confidence level.

in a distant sea in the east of the Philippines and moved via the Philippines and the South China Sea towards the Indochina Peninsula to the west. A second pattern is a TC track that moved northerly from a distant sea in the east of the Philippines towards a distant sea in the east of Japan. During 1999 to 2013, a TC track showed a pattern that moved to the mid-latitude in East Asia mostly. Therefore, these patterns showed that TCs in 1999-2013 tended to move further to the high latitude than TCs in 1977-1998. That is, TC maximum intensity is likely to be found more in high latitudes in 19992013 than 1977-1998. In this regard, Wang and Chan [33] also showed that intensity of TCs that moved toward the midlatitude region in East Asia was much stronger than that of TCs that moved westerly toward the Indochina Peninsula or toward a distant sea in the east of Japan. They stressed that this strong intensity can be obtained because sufficient energy can be gotten from the sea while TCs moved toward the midlatitude in East Asia.

4.2. Large-Scale Environments. This study analyzed a difference of large-scale environments between two periods to determine the reason of the latitude shift of TC maximum intensity in recent years. In the difference of $500 \mathrm{hPa}$ streamline between two periods, anomalous anticyclonic circulations were strengthened in $30-50 \mathrm{~N}$, whereas anomalous monsoon trough was placed in the northern water of the South China Sea, which was extended to the east up to $145 \mathrm{E}$ (see Figure 3(a)). Therefore, as analyzed previously, TCs in 1999-2013 could be generated in much higher latitudes than TCs in 1977-1998. In addition, anomalous anticyclonic circulations were strengthened in the east of the anomalous monsoon trough. Therefore, a mid-latitude region in East
Asia was affected by the anomalous anticyclonic circulations and anomalous monsoon trough. This anomalous southeasterlies played a role in anomalous steering flows that directed TCs toward the mid-latitude in East Asia. Accordingly, as analyzed previously, anomalous pressure systems were formed in the mid-latitude region in East Asia that could affect TCs in 1999-2013 more than TCs in 1977-1998, which resulted in northerly latitude shift of TC maximum intensity in 1999-2013.

A difference of $850 \mathrm{hPa}$ streamline between two periods was also similar to a difference of $500 \mathrm{hPa}$ streamline between two periods (see Figure 3(b)). Anomalous anticyclonic circulations were strengthened in the mid-latitude of the analysis area, while anomalous monsoon trough was placed near Taiwan. In addition, anomalous southeasterlies were strengthened from the southeastern sea in the tropical and subtropical western North Pacific to the mid-latitude in East Asia.

A difference of OLR between two periods was studied (see Figure 4(a)). The smaller the OLR is, the stronger the convective activity is. Positive anomaly was strengthened in regions to the north of $25 \mathrm{~N}$, while negative anomaly was strengthened in regions to the south of $25 \mathrm{~N}$. This means that convective activity in 1999-2013 was strengthened more in the tropical and subtropical western North Pacific than in 1977-1998. Furthermore, the center of the negative anomaly was located in subtropical regions $(10-20 \mathrm{~N})$ rather than tropical regions, while the northern boundary of the negative anomaly was located up to the southwestern sea in Japan. Such results can be one of the factors that cause the northerly latitude shift of TC maximum intensity in recent years. In addition, as analyzed in the above, it was found that suitable 


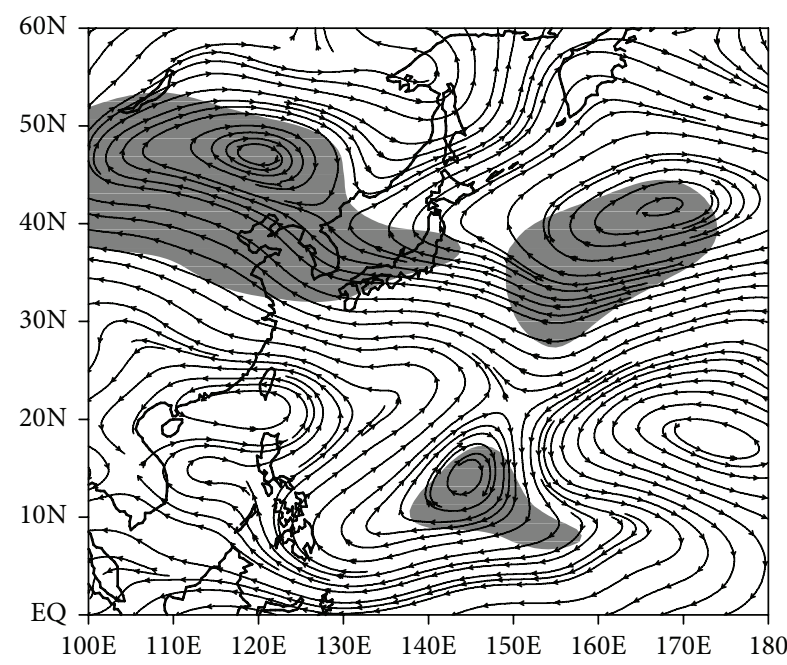

(a) $500 \mathrm{hPa}$ streamline

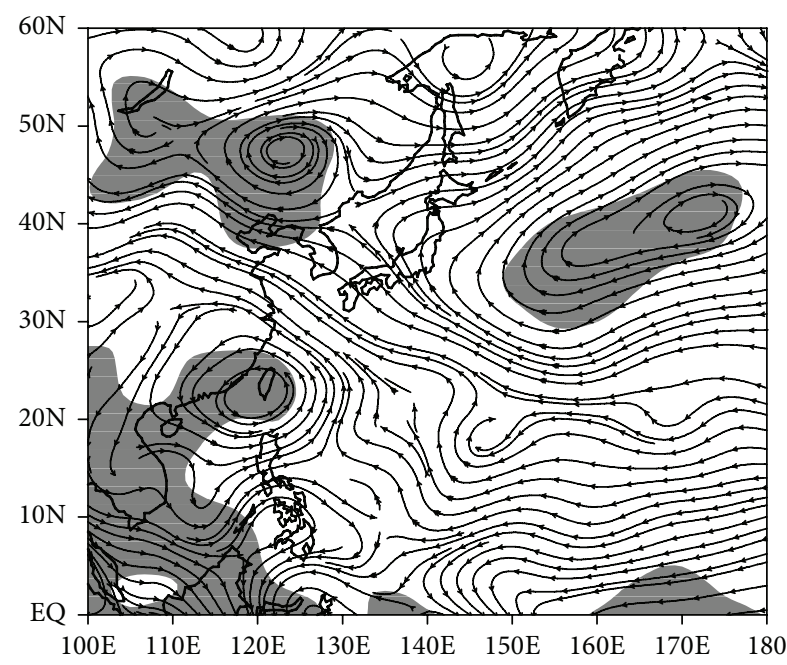

(b) $850 \mathrm{hPa}$ streamline

FIGURE 3: Differences in (a) $500 \mathrm{hPa}$ and (b) $850 \mathrm{hPa}$ streamline between the periods of 1999-2013 and 1977-1998. Shaded areas indicate that differences are significant at the $95 \%$ confidence level.

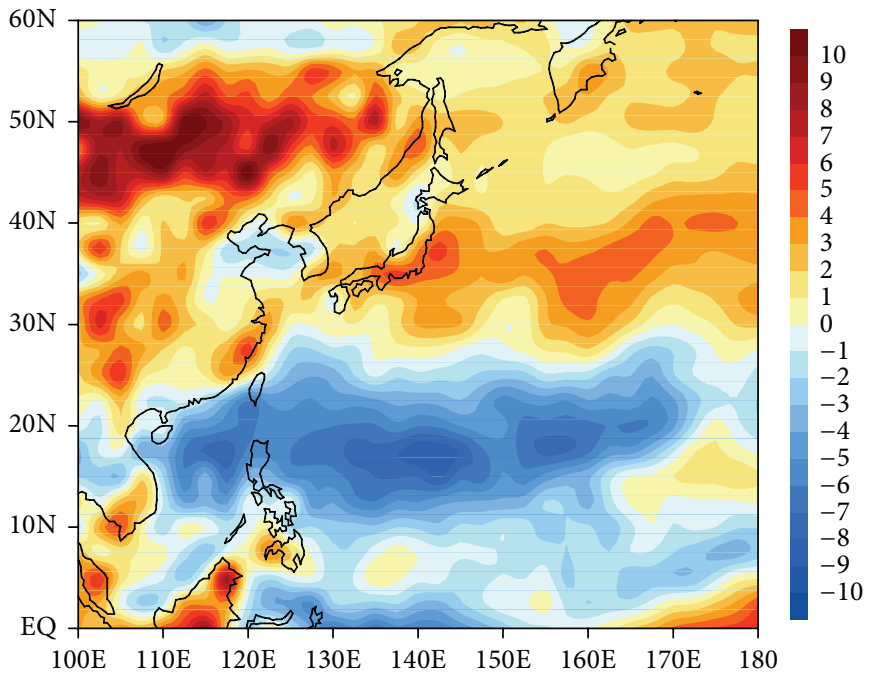

(a) Outgoing longwave radiation

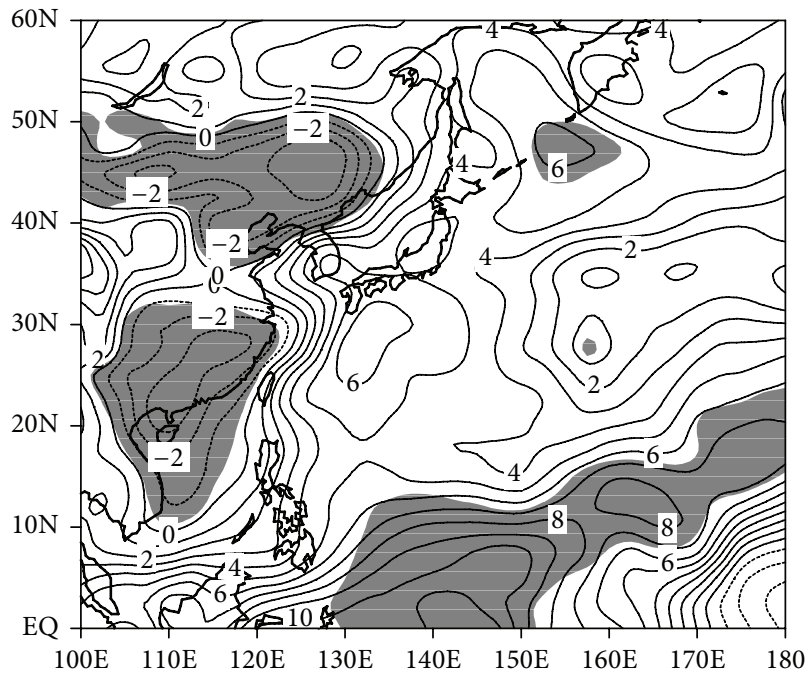

(b) $600 \mathrm{hPa}$ relative humidity

FIGURE 4: Same as in Figure 3, bur for (a) outgoing longwave radiation (OLR) and (b) $600 \mathrm{hPa}$ relative humidity. In (b), contour interval is $1 \%$ and shaded areas are significant at the $95 \%$ confidence level.

environments were formed so that TCs in 1999-2013 were generated further to the northern seas than TCs in 1977-1998 did.

Furthermore, this study analyzed a difference of $600 \mathrm{hPa}$ relative humidity between two periods (see Figure $4(\mathrm{~b})$ ). Negative anomaly was strengthened in East Asia continent, while positive anomaly was strengthened in the western North Pacific. Although the center of positive anomaly was located in the southeastern seas in the tropical western North Pacific, considerable anomaly values were also found in the southwestern sea in Japan. Therefore, these analysis results can also be one of the factors that cause the northerly latitude shift of TC maximum intensity in recent years.
Furthermore, this study analyzed a difference of $850 \mathrm{hPa}$ air temperature between two periods (see Figure 5(a)). In all of the analysis regions, warm anomaly was found. A magnitude of warm anomaly was higher in the western North Pacific than in East Asia continent. This result can also be one of the factors that cause the northerly latitude shift of TC maximum intensity in recent years.

A difference of $850 \mathrm{hPa}$ relative vorticity between two periods was also analyzed (see Figure 5(b)). Positive anomaly was located in $20-30 \mathrm{~N}$, whereas negative anomaly was strengthened in tropical regions. This means that not only environments where TCs in 1999-2013 could be generated more frequently in higher latitude than TCs in 1977-1998 


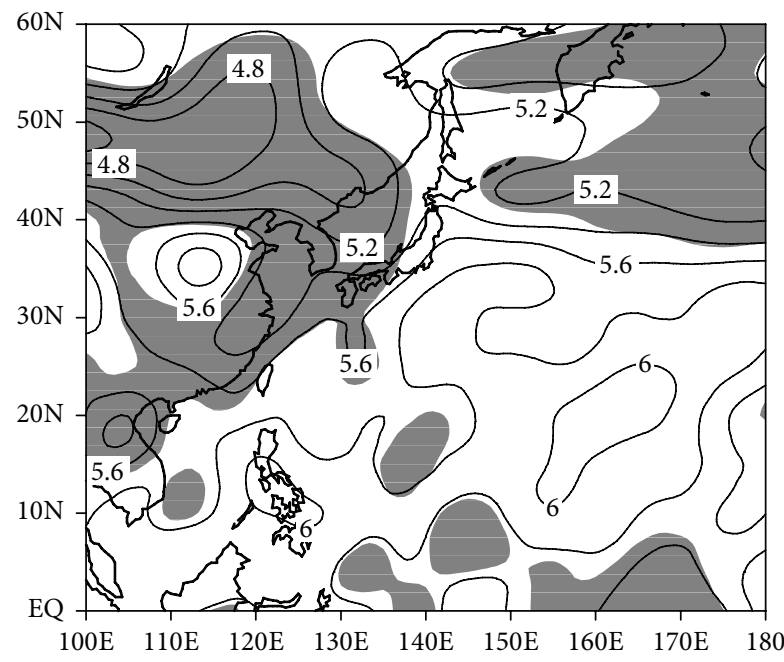

(a) $850 \mathrm{hPa}$ air temperature

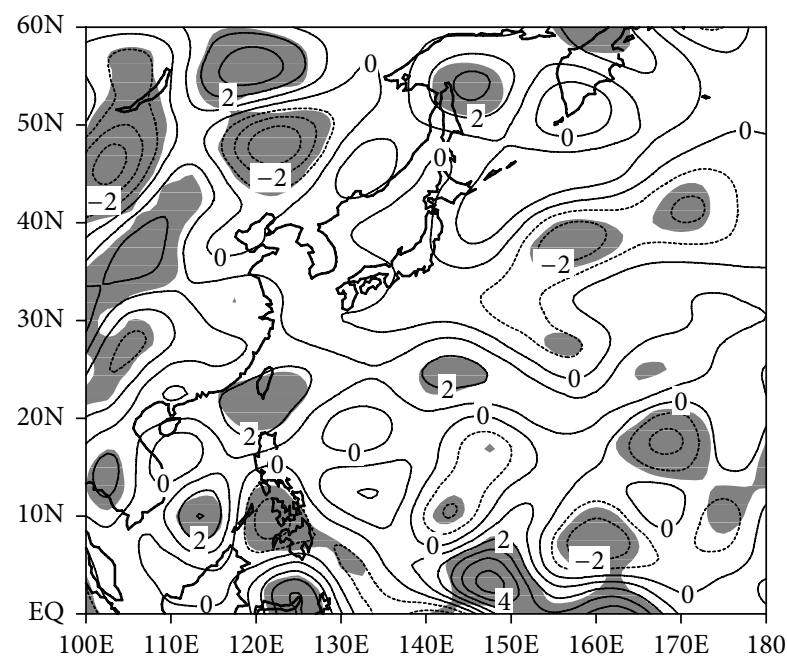

(b) $850 \mathrm{hPa}$ relative vorticity

Figure 5: Same as in Figure 3, bur for (a) $850 \mathrm{hPa}$ air temperature and (b) $850 \mathrm{hPa}$ relative vorticity. Contour intervals are $0.2^{\circ} \mathrm{C}$ for $850 \mathrm{hPa}$ air temperature and $1 \times 10^{-6} \mathrm{~s}^{-1}$ for $850 \mathrm{hPa}$ relative vorticity. Shaded areas are significant at the $95 \%$ confidence level.

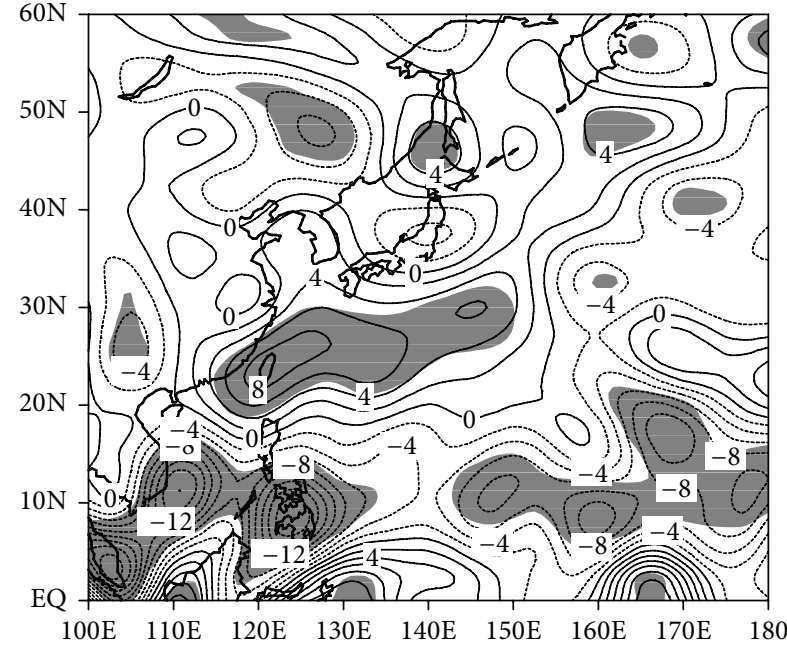

(a) $200 \mathrm{hPa}$ divergence

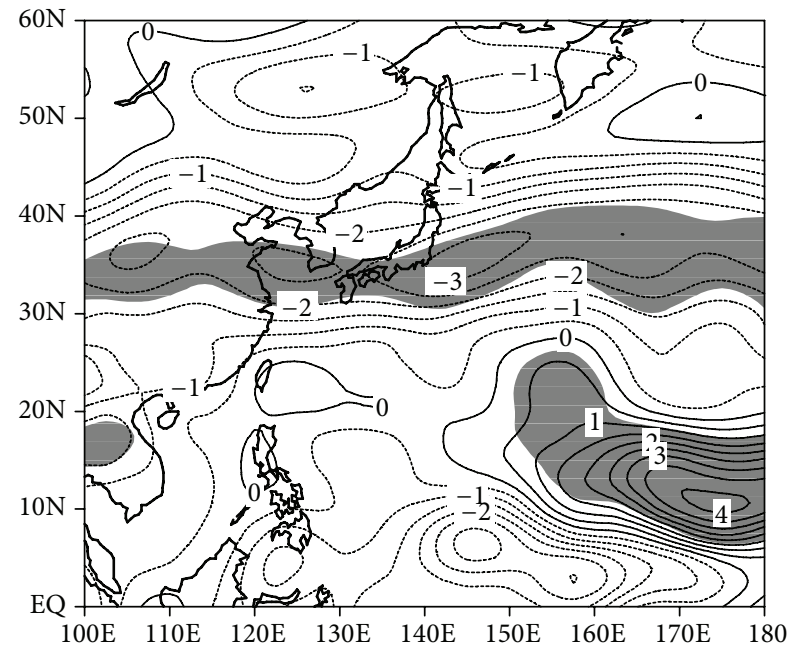

(b) Vertical wind shear $(200-850 \mathrm{hPa})$

Figure 6: Same as in Figure 3, bur for (a) $200 \mathrm{hPa}$ divergence and (b) vertical wind shear between $200 \mathrm{hPa}$ and $850 \mathrm{hPa}$. Contour intervals are $2 \mathrm{~ms}^{-1}$ for $200 \mathrm{hPa}$ divergence and $0.5 \mathrm{~ms}^{-1}$ for vertical wind shear between $200 \mathrm{hPa}$ and $850 \mathrm{hPa}$. Shaded areas are significant at the $95 \%$ confidence level.

were formed but also can be a factor that results in more northerly latitude shift of TC maximum intensity in recent years.

This study also analyzed a difference of $200 \mathrm{hPa}$ divergence between two periods (see Figure 6(a)). Negative anomaly was strengthened in the south of $20 \mathrm{~N}$, whereas positive anomaly was strengthened in $20-30 \mathrm{~N}$ (from Taiwan to the southern sea in Japan). This meant that anomalous convergence was strengthened in the upper atmosphere of the south to $20 \mathrm{~N}$, thereby forming anomalous downward flows, whereas anomalous divergence was strengthened in the upper atmosphere in $20-30 \mathrm{~N}$, thereby forming anomalous upward flows. Such result means that not only environments where TCs in 1999-2013 could be generated more frequently in higher latitude than TCs in 1977-1998 were formed but also can be a factor that results in more northerly latitude shift of TC maximum intensity in recent years.

$200-850 \mathrm{hPa}$ vertical wind shear could also influence TC genesis and TC intensification. Therefore, this study analyzed a difference of $200-850 \mathrm{hPa}$ vertical wind shear between two periods (see Figure 6(b)). Except for eastern seas in the subtropical western North Pacific, most regions in the analysis areas showed negative anomaly. This meant that an atmospheric structure, which was advantageous to strengthening of TC genesis and TC intensity, was formed because structures of the upper and lower troposphere layers 


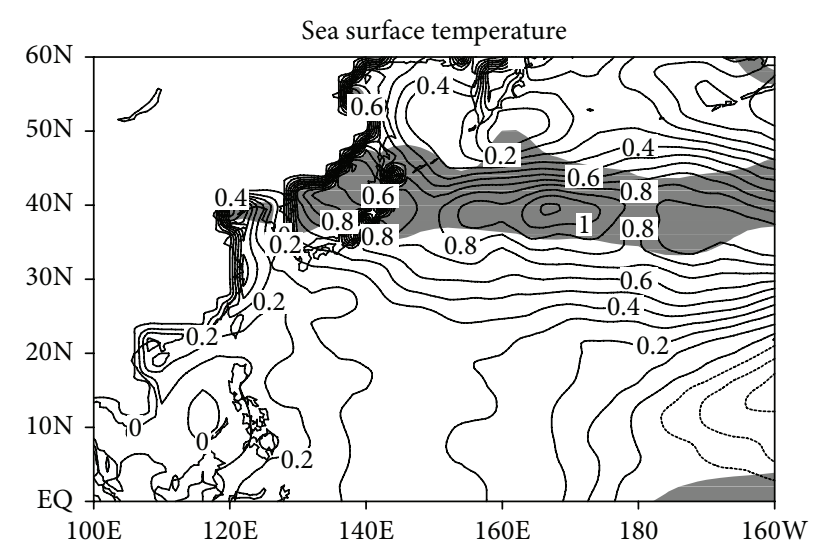

Figure 7: Same as in Figure 3, bur for sea surface temperature. Contour interval is $0.1^{\circ} \mathrm{C}$. Shaded areas are significant at the $95 \%$ confidence level.

were stabilized as values of $200-850 \mathrm{hP}$ vertical wind shear became smaller. In particular, the largest negative anomaly was shown in the mid-latitude zone. Therefore, this result can be one of the factors that cause the northerly latitude shift of TC maximum intensity in recent years.

SST can also be a factor that can influence TC genesis and TC intensity. Thus, a difference of SST between two periods was analyzed in this study (see Figure 7). Warm anomaly was found in all waters in the analysis regions except for eastern seas in the tropical western Pacific. In particular, a center of warm anomaly was located in the sea in the mid-latitude. Therefore, even if TCs can move to the seas in the midlatitude, strong TC intensity can be maintained by the warm SST anomaly. Therefore, this result can also be one of the factors that cause the northerly latitude shift of TC maximum intensity in recent years.

\section{Summary and Conclusion}

The present study obtained latitudes when tropical cyclones (TCs) had maximum intensity and applied statistical changepoint analysis to the averaged time series of yearly data. The analysis result showed that latitudes of the maximum intensity of TCs have increased since 1999. Then, to determine the reason for this increase, we have analyzed a difference of the means between period of 1999-2013 and 1977-1988.

First, with respect to the TC genesis frequency, TCs during 1999 to 2013 were generated more frequently in the northwest waters in the tropical and subtropical western North Pacific than TCs during 1977 to 1998. Accordingly, northerly latitude shift of not only TC maximum intensity but also TC genesis location was found in the data.

There was also a big difference of TC tracks between two periods. TCs over the period 1977-1998 showed a northward track trend generated mostly from the distant sea in the east of the Philippines via the mainland of the Philippines and South China Sea to the west toward Indochina or from the distant sea in the east of the Philippines to the distance sea in the east of Japan. On the contrary, TCS over the period of 1999-2013 showed a northward move pattern to the midlatitude region in East Asia mostly. Therefore TCs over the period of 1999-2013 tended to move to much higher latitudes than TCs over the period of 1977-1998, which also resulted in high possibility of TC maximum intensity occurred in higher latitudes during the former period than during the latter period.

In the difference of $500 \mathrm{hPa}$ streamline between two periods, anomalous anticyclonic circulations were strengthened in $30-50 \mathrm{~N}$ whereas anomalous monsoon trough was placed in the north of the South China Sea, which was extended to the east up to 145E. Therefore, TCs in 1999-2013 could be generated in much higher latitudes than TCs in 1977-1998. Furthermore, the mid-latitude in East Asia was affected by the anomalous southeasterlies due to the above anomalous anticyclonic circulations and anomalous monsoon trough and the anomalous southeasterlies played a role in anomalous steering flows that directed TCS to the mid-latitude regions in East Asia, which made TCs in 1999-2013 to have more influence in the mid-latitude region in East Asia than TCs in 1977-1998 did. Because of this, the former period had to shift latitudes of TC maximum intensity northerly.

A difference of OLR between two periods showed that a center of the negative anomaly was located in subtropical region rather than in tropical regions, while the northern boundary of the negative anomaly was moved up to the southern sea of Japan. In addition, a difference of $600 \mathrm{hPa}$ relative humidity showed that positive anomaly was strengthened in the southern seas of Japan, which not only made TCs in 1999-2013 to be generated in higher latitudes but also shifted latitudes of TC maximum intensity further to the north.

Furthermore, analysis result with regard to a difference of $850 \mathrm{hPa}$ air temperature between two periods showed warm anomaly in most of the analysis regions, while $850 \mathrm{hPa}$ relative vorticity showed that positive anomaly was strengthened in 20-30N rather than tropical regions, thereby shifting latitudes of TCs in 1999-2013 of maximum intensity further to the north.

Analysis result on a difference of $200 \mathrm{hPa}$ divergence between two periods showed that positive anomaly was strengthened from regions near Taiwan to the southern seas of Japan, which meant that anomalous upward flows were formed over these latitudes. These results hinted that not only TCs in 1999-2013 could be generated in higher latitudes but also latitudes of TC maximum intensity could be shifted further to the north than TCs in 1977-1998 could.

Furthermore, analysis results on a difference of 200$850 \mathrm{hPa}$ vertical wind shear between two periods showed that negative anomaly was shown in most analysis regions. Analysis on a difference of SST also showed that the highest warm anomaly was shown in the mid-latitude in East Asia, which could be one of the factors that can shift latitudes of TC maximum intensity further to the north in recent years.

The present study simply analyzed reasons for the shift on latitude change of TC maximum intensity in recent years. For the future study, such reasons found in this study will be verified through regional climate models. 


\section{Conflict of Interests}

The authors declare that there is no conflict of interests regarding the publication of this paper.

\section{Acknowledgment}

This work (15-2-40-41) was supported by Research Program funded by the DEGEC.

\section{References}

[1] K. Emanuel, "Increasing destructiveness of tropical cyclones over the past 30 years," Nature, vol. 436, no. 7051, pp. 686-688, 2005.

[2] J. H. Kim, C. H. Ho, and C. H. Sui, "Circulation features associated with the record-breaking typhoon landfall on Japan in 2004," Geophysical Research Letters, vol. 32, no. 14, 2005.

[3] S. K. Park and E. H. Lee, "Synoptic features of orographically enhanced heavy rainfall on the east coast of Korea associated with Typhoon Rusa (2002)," Geophysical Research Letters, vol. 34, no. 2, Article ID L02803, 2007.

[4] C. J. Pan, K. Krishna Reddy, H. C. Lai, and S. S. Yang, "Role of mixed precipitating cloud systems on the typhoon rainfall," Annales Geophysicae, vol. 28, no. 1, pp. 11-16, 2010.

[5] B. Lyon and S. J. Camargo, "The seasonally-varying influence of ENSO on rainfall and tropical cyclone activity in the Philippines," Climate Dynamics, vol. 32, no. 1, pp. 125-141, 2009.

[6] W. J. Yang and W. H. Yi, "Safety evaluation of masonry buildings for tsunami," Journal of Korean Society of Hazard Mitigation, vol. 13, no. 6, pp. 45-49, 2013.

[7] National Climatic Data Center (NOAA), State of the Climate: Hurricanes and Tropical Storms for Annual 2013, National Climatic Data Center (NOAA), Asheville, NC, USA, 2013.

[8] C. W. Landsea, "Counting Atlantic tropical cyclones back to 1900," EOS, vol. 88, pp. 197-208, 2007.

[9] D. S. R. Park, C. H. Ho, J. H. Kim, and H. S. Kim, "Strong landfall typhoons in Korea and Japan in a recent decade," Journal of Geophysical Research, vol. 116, no. D7, 2011.

[10] P. J. Webster, G. J. Holland, J. A. Curry, and H. R. Chang, "Changes in tropical cyclone number, duration, and intensity in a warming environment," Science, vol. 309, no. 5742, pp. 18441846, 2005.

[11] P.-S. Chu and J. D. Clark, "Decadal variations of tropical cyclone activity over the central north pacific," Bulletin of the American Meteorological Society, vol. 80, no. 9, pp. 1875-1881, 1999.

[12] H. Kamahori, N. Yamazaki, N. Mannoji, and K. Takahashi, "Variability in intense tropical cyclone days in the western North Pacific," SOLA, vol. 2, pp. 104-107, 2006.

[13] J. B. Elsner, J. P. Kossin, and T. H. Jagger, "The increasing intensity of the strongest tropical cyclones," Nature, vol. 455, no. 7209, pp. 92-95, 2008.

[14] C. W. Landsea, N. Nicholls, W. M. Gray, and L. A. Avila, "Downward trends in the frequency of intense Atlantic hurricanes during the past five decades," Geophysical Research Letters, vol. 23, no. 13, pp. 1697-1700, 1996.

[15] C.-H. Ho, J.-J. Baik, J.-H. Kim, D.-Y. Gong, and C.-H. Sui, "Interdecadal changes in summertime typhoon tracks," Journal of Climate, vol. 17, no. 9, pp. 1767-1776, 2004.
[16] J. C. L. Chan and J.-E. Shi, "Long-term trends and interannual variability in tropical cyclone activity over the western North Pacific," Geophysical Research Letters, vol. 23, no. 20, pp. 27652767, 1996

[17] J. C. L. Chan, "Interannual and interdecadal variations of tropical cyclone activity over the western North Pacific," Meteorology and Atmospheric Physics, vol. 89, no. 1, pp. 143-152, 2005.

[18] A. Z.-C. Goh and J. C. L. Chan, "Interannual and interdecadal variations of tropical cyclone activity in the South China Sea," International Journal of Climatology, vol. 30, no. 6, pp. 827-843, 2010.

[19] J. Lighthill, "Global climate change and tropical cyclones," Bulletin American Meteorological Society, vol. 75, no. 11, pp. 2147-2157, 1994.

[20] P. J. Klotzbach, "Trends in global tropical cyclone activity over the past twenty years," Geophysical Research Letters, vol. 33, no. 10, Article ID L10805, 2006.

[21] M. C. Bove, D. F. Zierden, and J. J. O’Brien, "Are Gulf landfalling hurricanes getting stronger?" Bulletin of the American Meteorological Society, vol. 79, no. 7, pp. 1327-1328, 1998.

[22] J. P. Kossin, K. A. Emanuel, and G. A. Vecchi, “The poleward migration of the location of tropical cyclone maximum intensity," Nature, vol. 509, no. 7500, pp. 349-352, 2014.

[23] K. Choi, K. Park, J. Kim, and B. Kim, "Synoptic analysis on the trend of northward movement of tropical cyclone with maximum intensity," Journal of the Korean earth science society, vol. 36, no. 2, pp. 171-180, 2015.

[24] E. Kalnay, M. Kanamitsu, R. Kistler et al., "The NCEP/NCAR 40-year reanalysis project," Bulletin of the American Meteorological Society, vol. 77, no. 3, pp. 437-471, 1996.

[25] R. Kistler, "The NCEP/NCAR 50-year reanalysis," Bulletin of the American Meteorological Society, vol. 82, pp. 247-267, 2001.

[26] B. Liebmann and C. A. Smith, "Description of a complete (interpolated) outgoing longwave radiation dataset," Bulletin of the American Meteorological Society, vol. 77, pp. 1275-1277, 1996.

[27] R. W. Reynolds, N. A. Rayner, T. M. Smith, D. C. Stokes, and W. Wang, "An improved in situ and satellite SST analysis for climate," Journal of Climate, vol. 15, no. 13, pp. 1609-1625, 2002.

[28] C.-H. Ho, J.-H. Kim, H.-S. Kim, C.-H. Sui, and D.-Y. Gong, "Possible influence of the Antarctic oscillation on tropical cyclone activity in the Western North Pacific," Journal of Geophysical Research, vol. 110, Article ID D19104, 2005.

[29] D. S. Wilks, Statistical Methods in the Atmospheric Sciences, Academic Press, New York, NY, USA, 1995.

[30] J. B. Elsner, T. H. Jagger, and X.-F. Niu, "Changes in the rates of North Atlantic major hurricane activity during the 20th century," Geophysical Research Letters, vol. 27, no. 12, pp. 17431746, 2000.

[31] P.-S. Chu, "Large-scale circulation features associated with decadal variations of tropical cyclone activity over the central North Pacific," Journal of Climate, vol. 15, no. 18, pp. 2678-2689, 2002.

[32] M. T. Wingo and D. J. Cecil, "Effects of vertical wind shear on tropical cyclone precipitation," Monthly Weather Review, vol. 138, no. 3, pp. 645-662, 2010.

[33] B. Wang and J. C. L. Chan, "How strong ENSO events affect tropical storm activity over the western North Pacific," Journal of Climate, vol. 15, no. 13, pp. 1643-1658, 2002. 

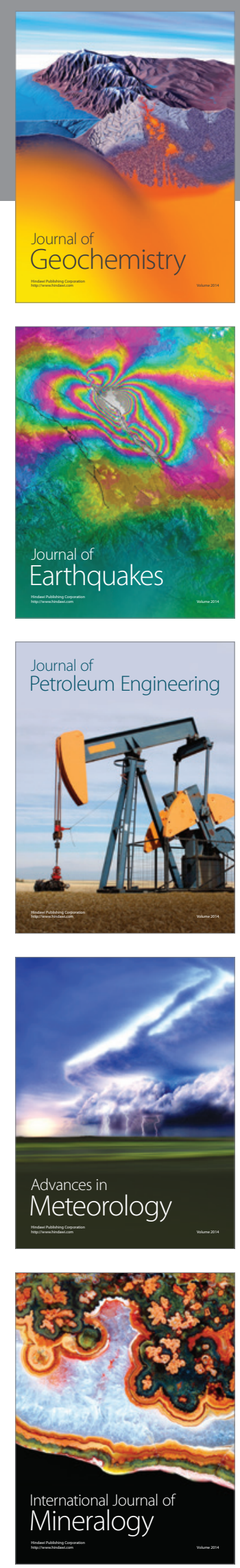
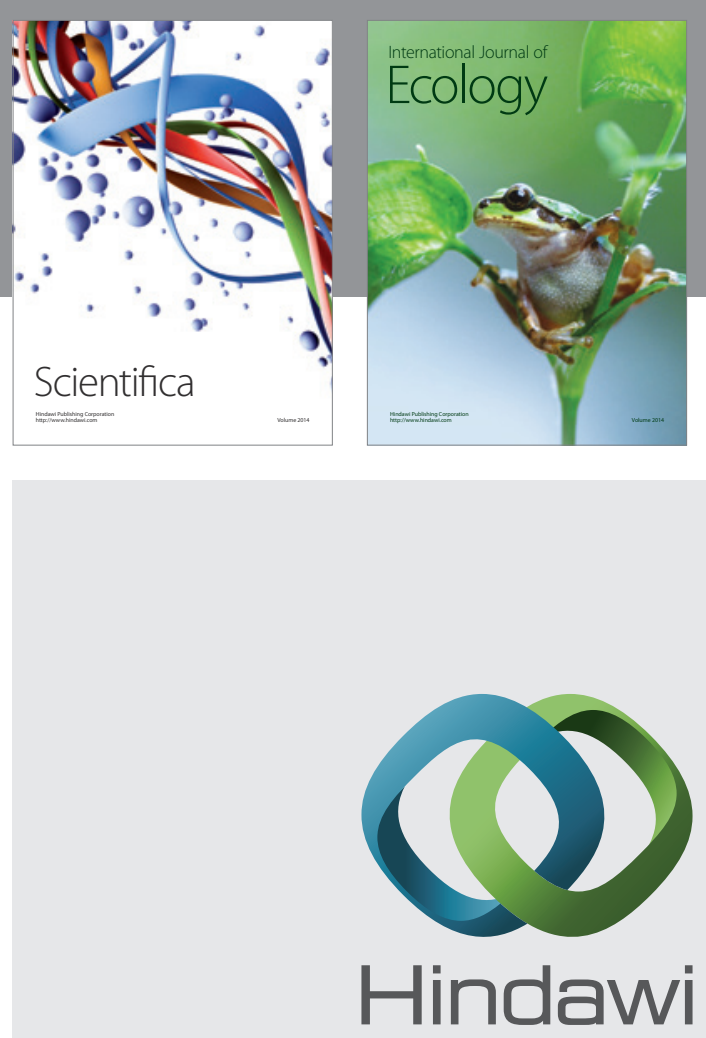

Submit your manuscripts at

http://www.hindawi.com
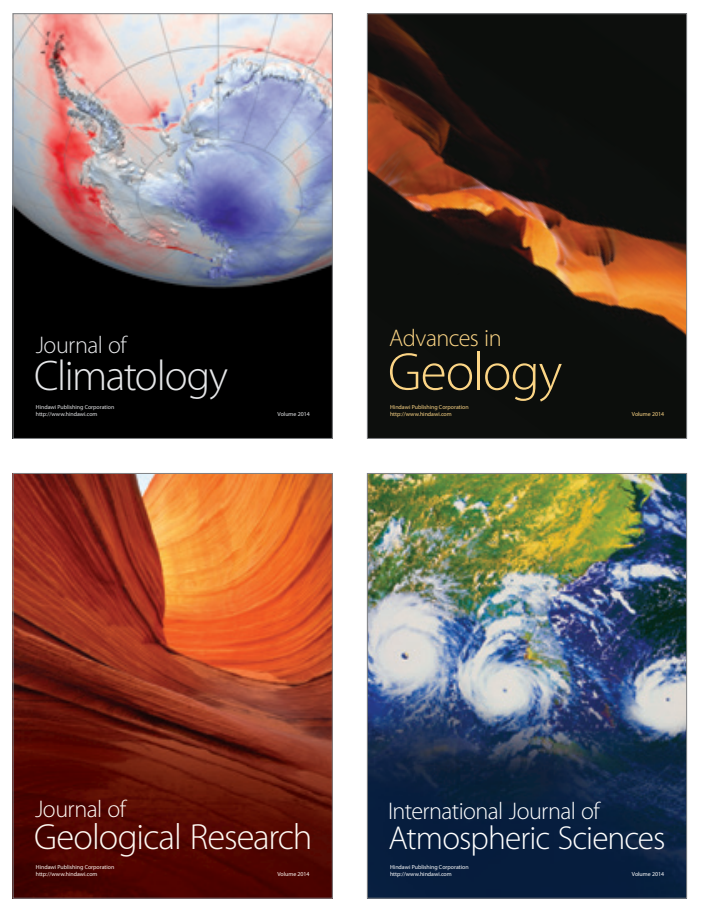

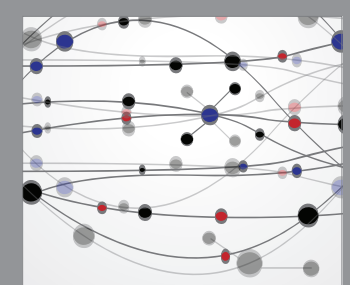

The Scientific

\section{World Journal}
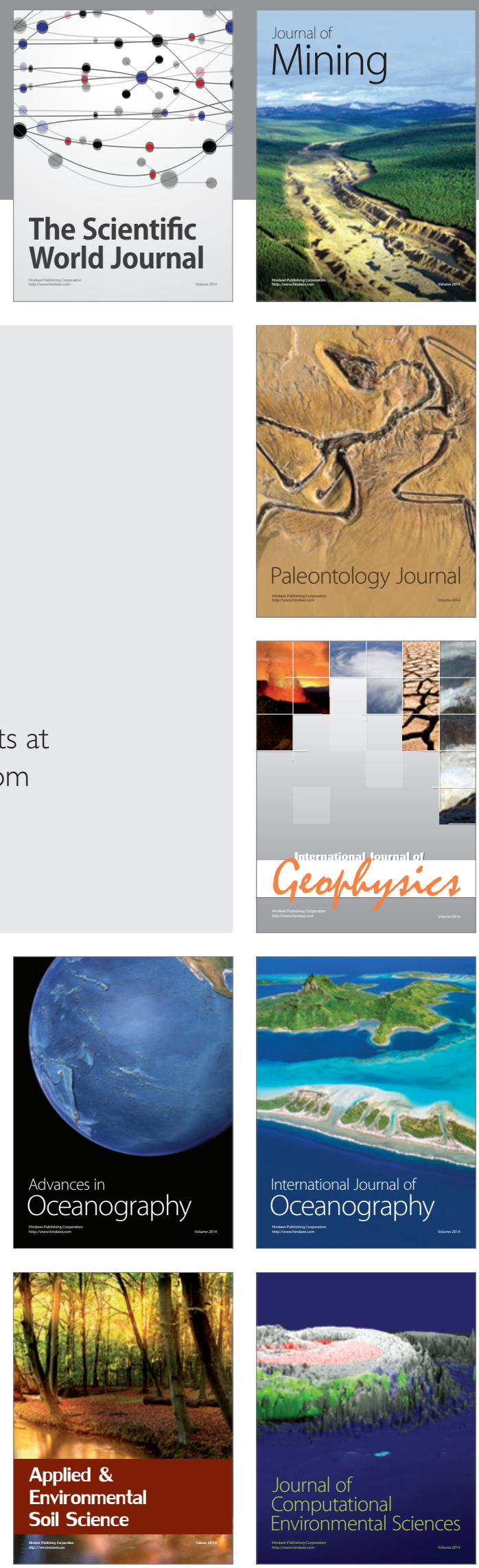